\title{
UNA NUEVA ETAPA
}

$\mathrm{U}$ na nueva etapa editorial se inicia en nuestra revista Biological Research. Luego de una exitosa labor realizada por el Dr. Manuel Krauskopf como Editoren-Jefe, que logró posicionar a la revista a nivel internacional, consiguiendo un nivel de impacto ISI significativo e histórico, por lo cual la Sociedad de Biología de Chile le está enormemente agradecida, asume a partir de este número el Dr. Jorge Garrido, quien hasta la fecha se desempeñaba como Editor Asociado. A nombre de nuestra Sociedad de Biología, también deseamos reconocer y agradecer el trabajo realizado por el equipo de Editores Asociados y miembros del Comité Editorial.

El nuevo Editor-en-Jefe se encuentra estructurando el nuevo Comité Editorial, al cual ya se han incorporado algunos distinguidos miembros de la comunidad científica nacional e internacional, y esperamos que superados los retrasos debido a los cambios en los planteles editoriales, nuestra Revista Biological Research continúe liderando entre las publicaciones científicas originadas en Latinoamérica y se sitúe cada vez mejor en el amplio espectro de revistas internacionales indexadas.

El impacto de Biological Research dependerá siempre de la calidad de los artículos científicos que publique, y ello es consecuencia de que los científicos que realizan investigación de punta en nuestro país y en el mundo escojan a nuestra revista con elevada prioridad para la publicación de sus resultados.

\section{DR. MANUEL J. SANTOS}

Presidente de la Sociedad de Biología de Chile 2007-2008 
